\title{
Five thousand years of irrigation history in Iran: rituals and methods
}

\author{
M. Sadrzadeh ${ }^{1} \&$ G. Badalians Gholikandi ${ }^{2}$ \\ ${ }^{I}$ Faculty of Foreign Languages and Literature, Tehran University, Iran \\ ${ }^{2}$ Power and Water University of Technology (PWUT), \\ Water Research Institute (WRI), Iran
}

\begin{abstract}
Iran's geographical location and the low availability of water resources are the reasons for water receiving a special sanctum. Water has a mythic root in Iranian culture that has been used in tales and stories. The first official and documented knowledge of irrigation, water sharing and its use in ancient Iran dates back more than five thousand years. Ancient structures and customs that have been deeply rooted in Iran's history can still be found in several parts of the country. In this research, special customs such as invokes for the start of or the end of rain (sun invoke), as well as flood irrigation and constructed structures over the last 2500 years, were surveyed in central parts of Iran. In regard to water distribution systems and their importance in dry and semi-dry areas, the results of irrigation system of ancient Drakan city and its countryside in Fars province of 10-13 A.D. were studied.

One of the conventional water resources management systems in ancient Iran was the water intake from saline rivers in specific seasons of the year, and several weirs, intakes and channels were constructed. In this study, survey results of the Abshour River that was located beside Fadami plain, Darab, on today's border of Fars and Hormozgan provinces, and constructed structures for the irrigation of local plains 1300-1500 years ago are given.
\end{abstract}

Keywords: water, ancient Iran, irrigation, Fars, Drakan.

\section{Introduction}

Iran's geographical location and low available water resources have caused Iranians to search widely for water, which also has had a special value and 
sanctity. Iranians always know the water as a source of godsend and welfare, so they have special customs for worship and thanks.

Water has been so important that Iranians have called their provenance "water and land" [1]. Rainfall invokes, or those for the end of rain, have been some of the peoples' beliefs about water. Many proverbs and phrases about water can be found in Iranian culture. Water has a mythic root in Iranian culture. According to the historical documents and also Ferdosi's Shahnameh, Houshang (the king of Achaemenid dynasty) taught people irrigation methods, Deim and water farming, and wheat reaping. Hence, the first document about the irrigation history of Iran is from about five thousand years ago [2].

The ancient Iranians have been known not only for their science and technology in water structures, but also they were famous in the management and organization of water resources. In the Sasanian era, and years after that, an integrated rule, Namak, was written and applied, and a "Divan kast fozud" organization acted on the bases of that rule. This organization was a powerful organization that controlled the construction of water structures and their operations and maintenance. Moreover, this organization resolved water sharing issues between people, determining and registering water shares based on the Namak rule [3].

\section{Water uses for irrigation and mill operation}

In ancient Iran, water transfer from springs to the point of use and proper sharing were always important (for example the "Drakan" city in Fars province).

In the remaining geographical documents of 700-1000 years ago, a city was named Drakan or Darkan which is omitted in today's maps. Today, a city ruined by an earthquake is located $2 \mathrm{~km}$ to the southeast of the Darakou village (Tal Narenjoon) and researchers believe that that city is Drakan city.

In the debris of the Drakan city, many signs of stony and concrete canals and tanks were found. In addition, water structures in the city and country reveals that water was transferred from long distances. First, water storage tanks were filled, and then water was transferred to the farms. Some mills were constructed and installed in the flow of water canals to utilise the application of water energy.

Drakan city is located in a situation surrounded by farming lands, so several water structures should be constructed in that valley for proper water supply to farms. Abdalan, Abareh, Savareh, Canals, Tondabeh and Siphons are such of those structures. The required drinking water of inhabitants were supplied from mountainous paths by stony and concrete canals and stored in storage tanks. The remarkable point in Drakan city is that inhabitants weren't losing excess water and were conducting excess water to their farms [4].

\section{Water transfer structures}

There are many mountains and valleys in extent parts of Iran. Research shows that different water transfer structures have been applied since three thousand 


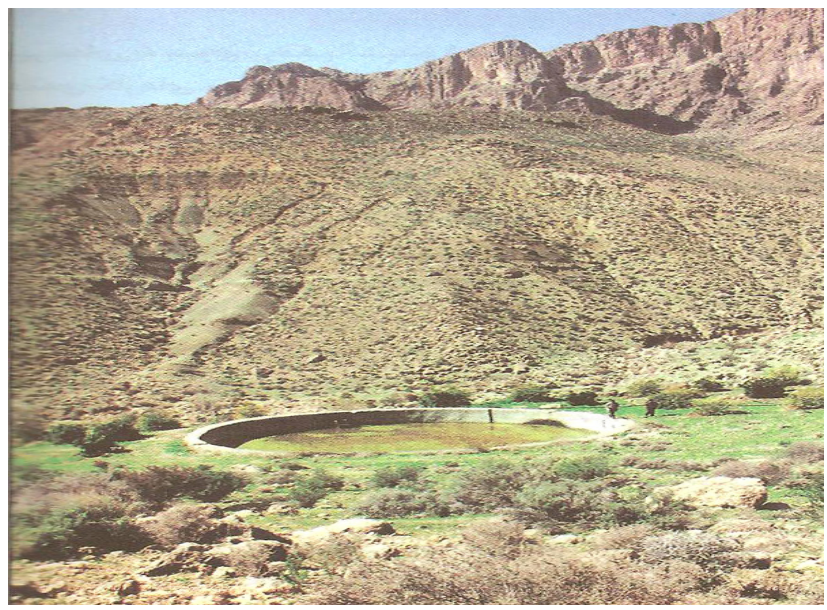

Figure 1: $\quad$ The Makhak pond.

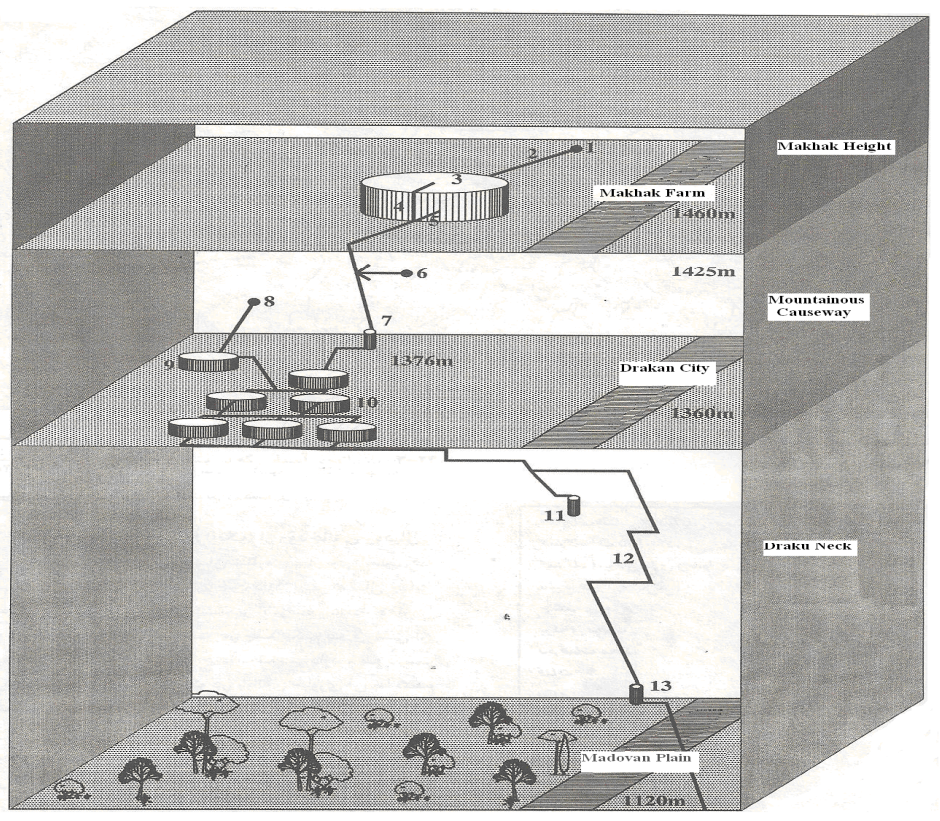

Figure 2: Water distribution from Makhak farm $(1460 \mathrm{~m})$ to Drakan city (1360 m) and Madovan plain (1320 m). 1- Jarm Sangi spring, 2water canal, 3- Makhak pond, 4- weir, 5- hatch, 6- canal 7- mill 8canal, 9- canal pond, 10- Drakan ponds, 11- mill, 12- water canal, 13- mill. 
78 Sustainable Irrigation Management, Technologies and Policies III

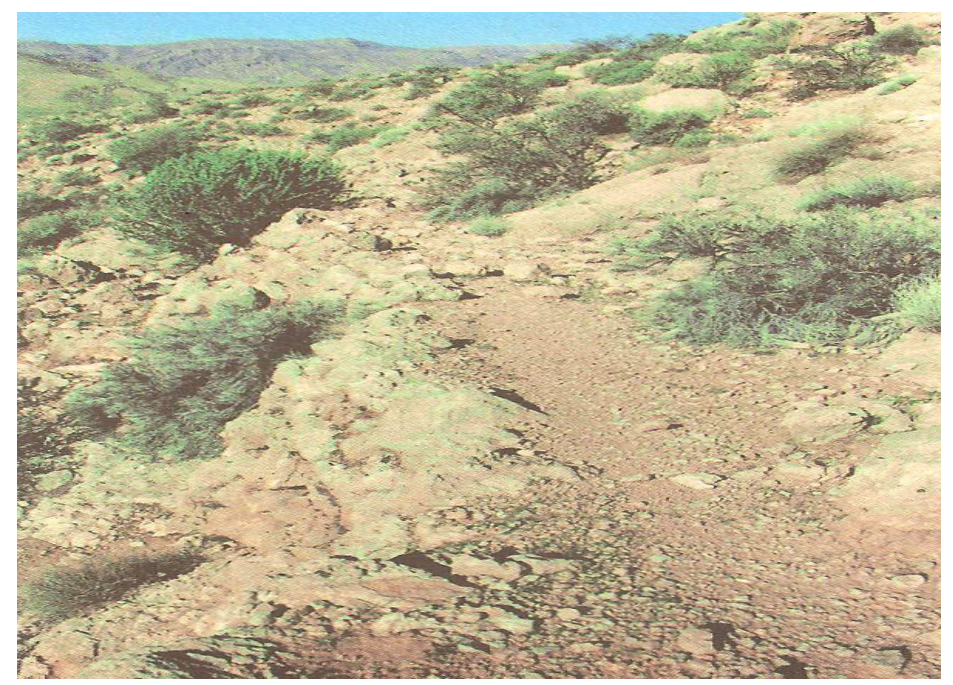

Figure 3: Water distribution canal from Makhak to Drakan city.

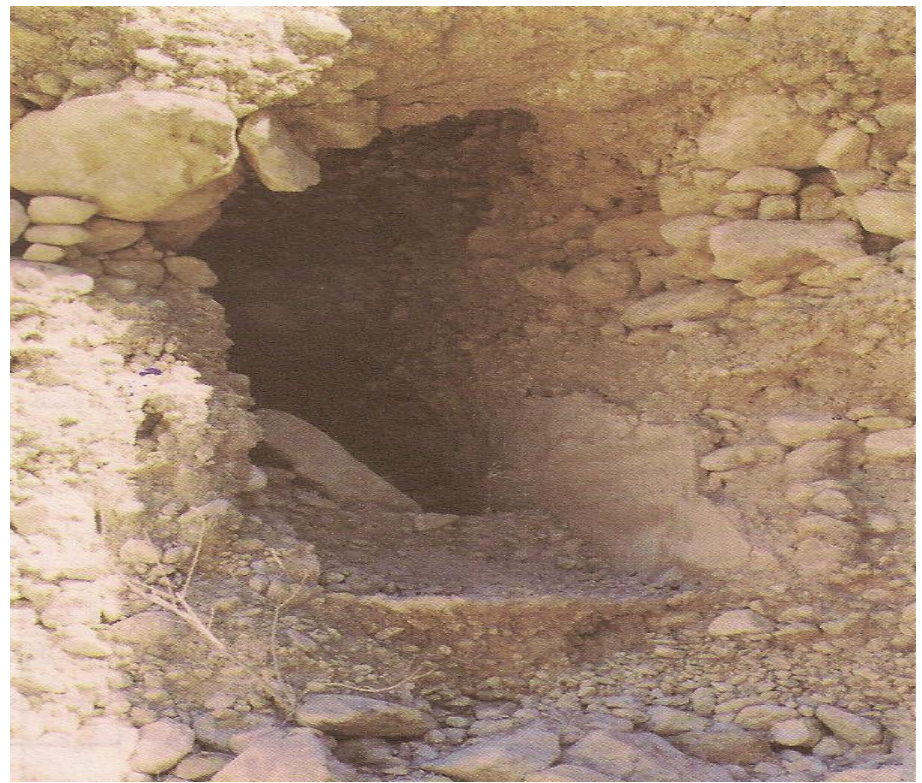

Figure 4: Canal stucco for prevention from water infiltration. 


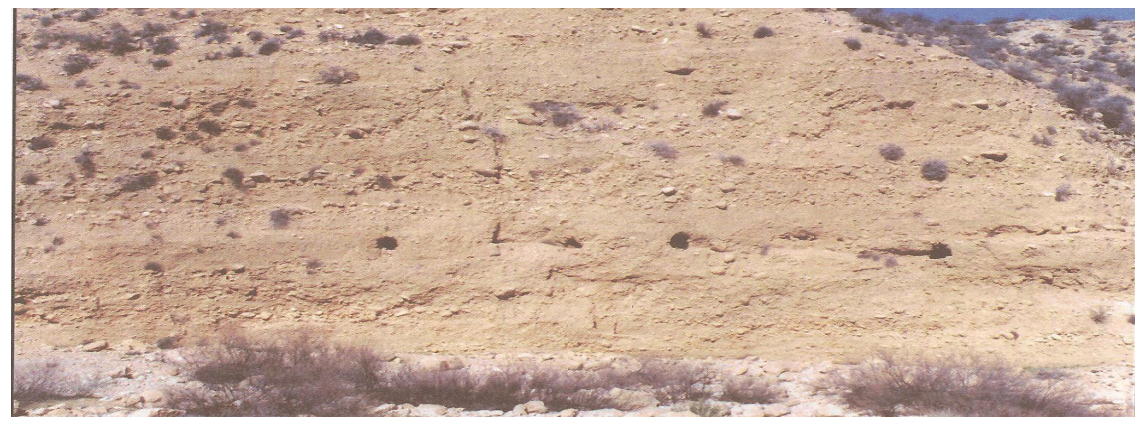

Figure 5: $\quad$ Orifices in water canals for Madovan farms irrigation.

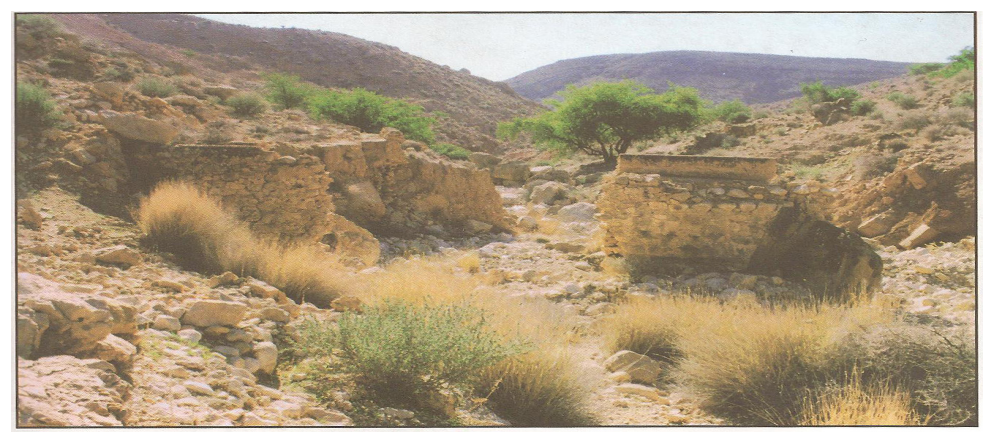

(a)

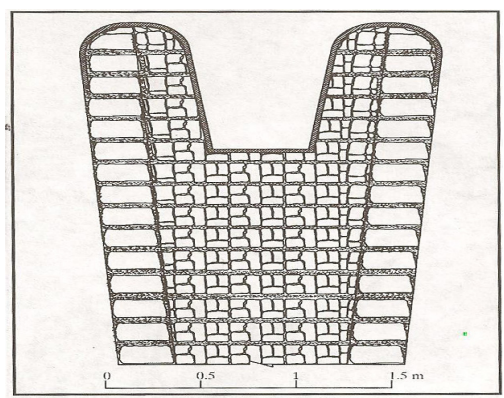

(b)

Figure 6: Ruined weir on Darakou valley stream: (a) direct view; (b) crosssectional view. 
80 Sustainable Irrigation Management, Technologies and Policies III

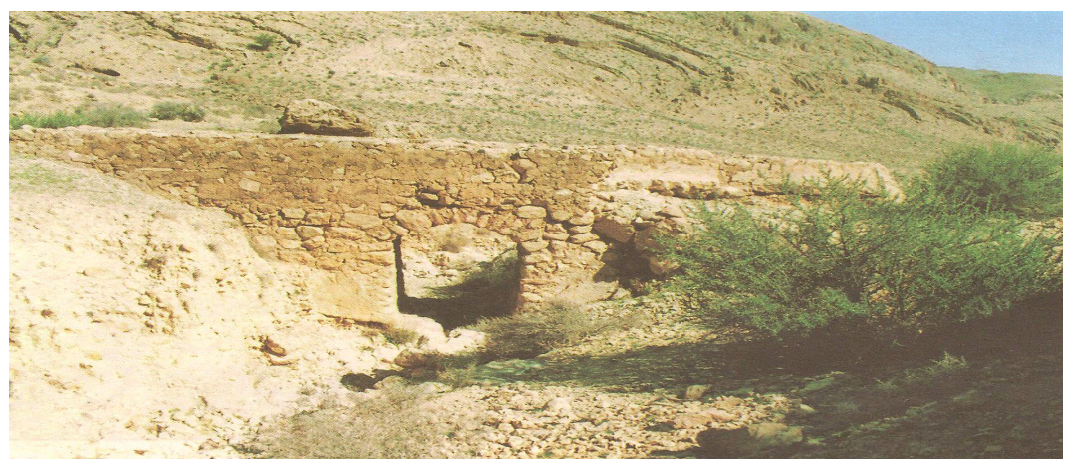

(a)

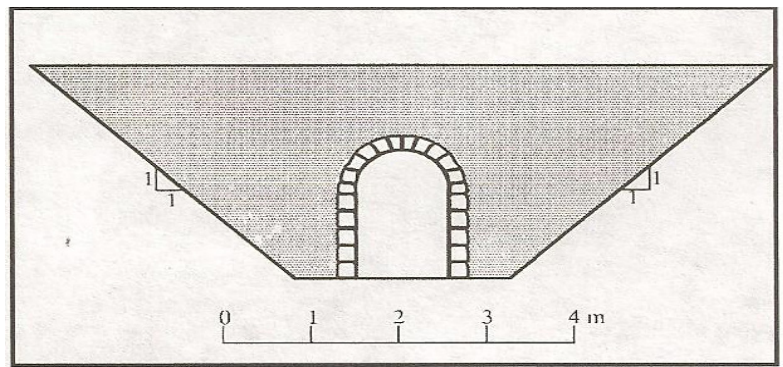

(b)

Figure 7: A water distribution weir from Drakan city to Madovan plain: (a) direct view; (b) cross-sectional view.

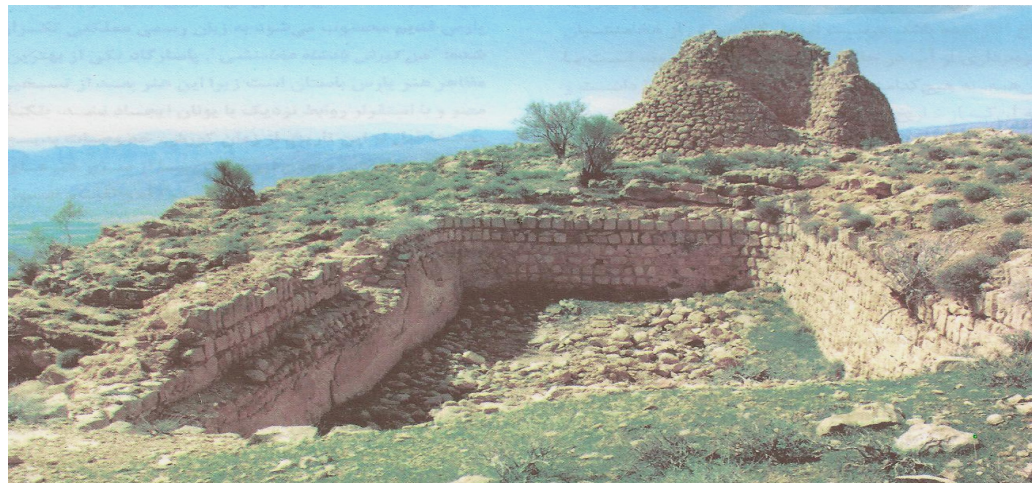

Figure 8: $\quad$ Two ponds at Dokhtar Darakou castle. 


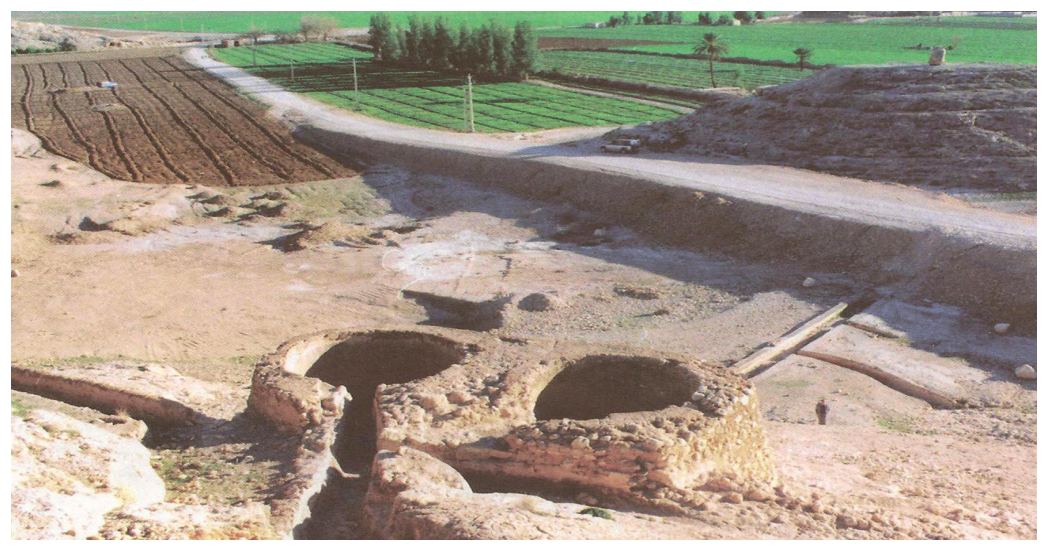

Figure 9: $\quad$ Scheme of the twin mill of Masjed Sangi.

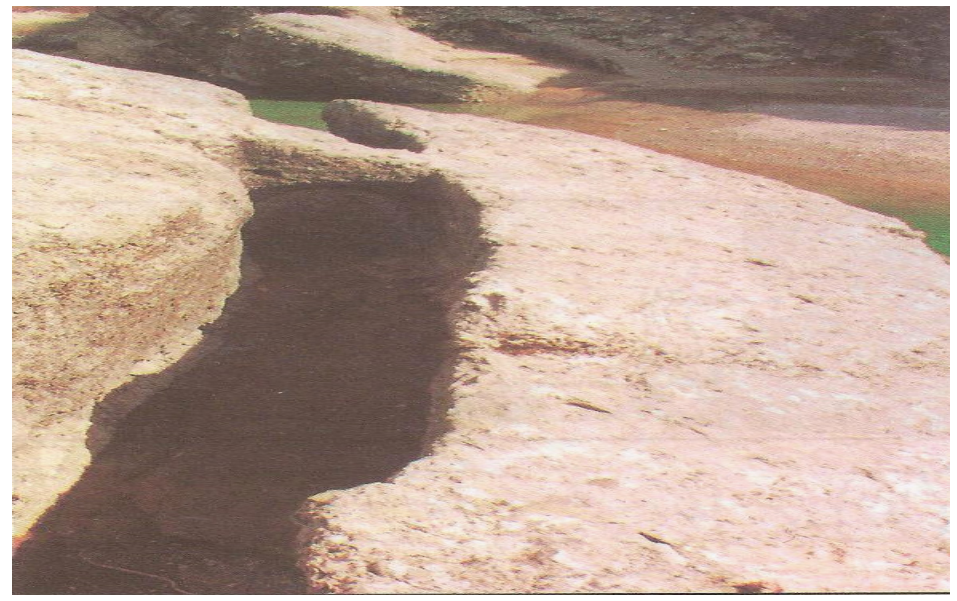

Figure 10: Quadrilateral shaped canal carved in a stone, Dehrood river.

years ago. One of the most popular is Jouy, which is named in English as a canal. The canal word is from the Ariaian language. In the Ariaian language, the word "Cal" was used in names of many streams and rivers [4].

\section{Rain invoking}

One of the similar aspects of most human customs is interest in the sky and its phenomenon. In general, rain invoking customs are more common in arid and semi-arid areas. In these areas, farming acts have been based on rain, especially in the spring season. The rain invoking costume has been important in most parts of Iran, especially in arid and semi-arid areas. Many reports about this field are related to Khorasan, Isfahan, Fars and Khouzestan provinces. The rain invoking custom has not been documented and similar to many other customs, has been 


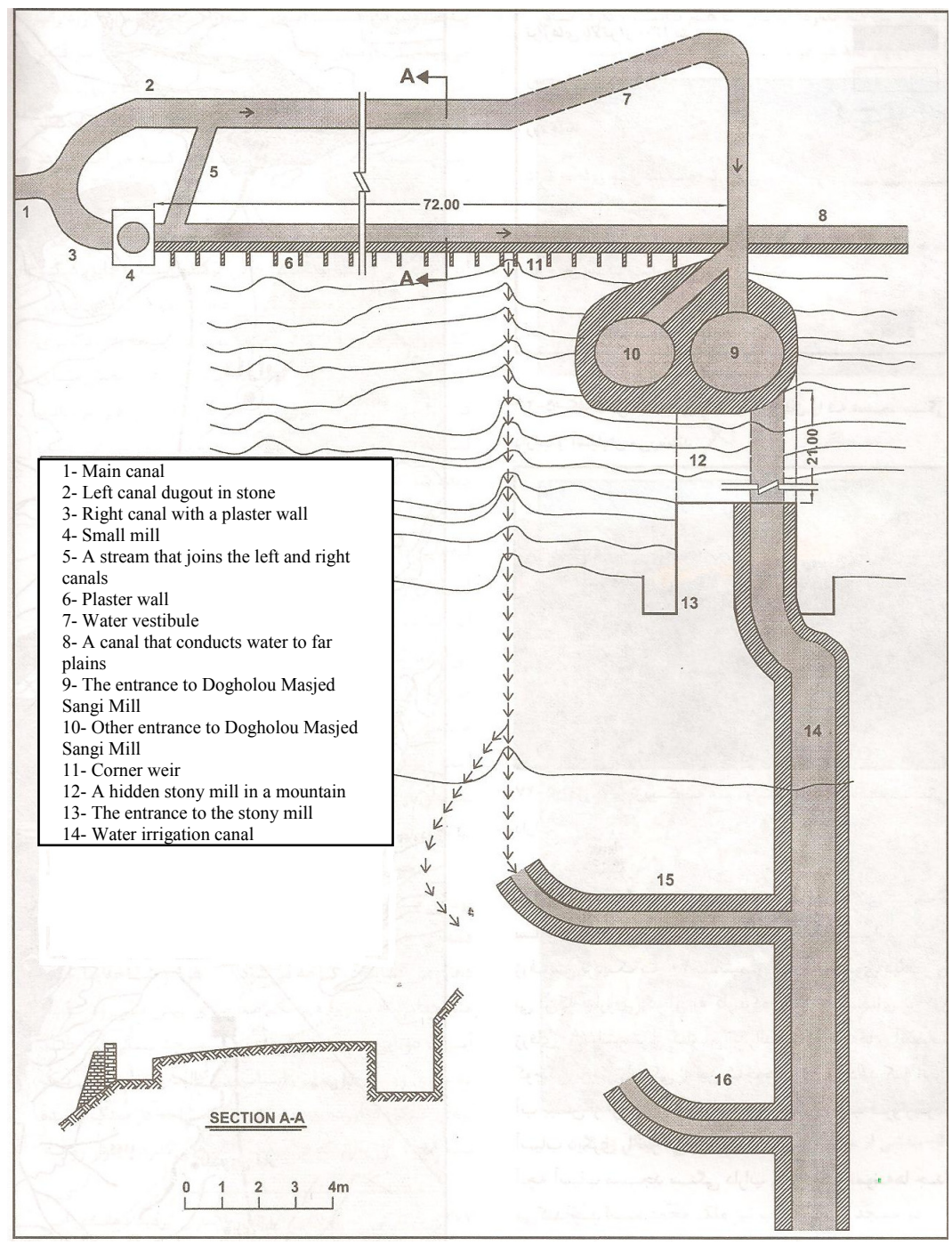

Figure 11: Several sections of the twin mill at Masjed Sangi in Darab.

unwritten, thus many changes have been entered in these customs. In ancient Iran, from the Hakemenenian era, the $13^{\text {th }}$ day of each month was a Rain Goddess day (Tashtar day). In the New Year, Iranians go out to the environment and in the midday that Malvolent Apoush (the black monster of drought) is set back by Tashtar, sacrifice a sheep to have a rainy and talented year. The ancient Iranians knew of "Anahita" as a water goddess and painted and worshipped her picture that had been in each shrine (Figure 15). 


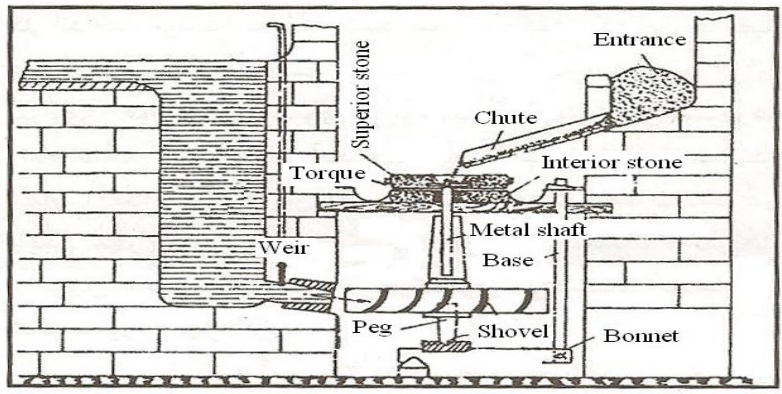

(a)

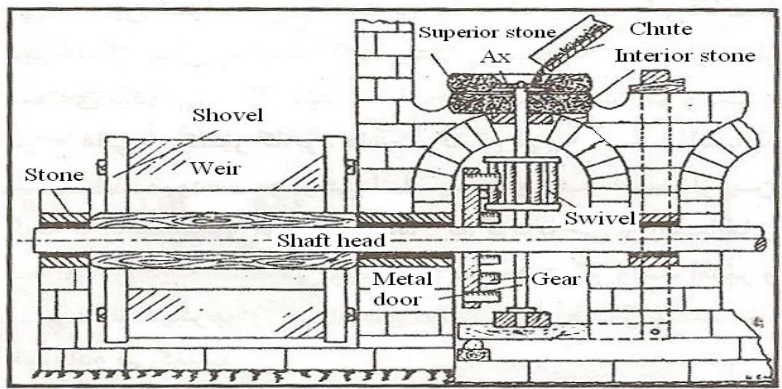

(b)

Figure 12: Ancient mills: (a) chute mill; (b) wheel mill.

In this custom, a manikin which may be the Rain Angel symbol, had several names in different areas or a man with long and postiche beard or a beardless man (drought symbol) was used and some poems and lampoons were sung by youths about them. Sometimes people with their babies went out into the plains to invoke for rain. The most interesting aspect of this custom is water pouring on the manikin or each other. By Islam propagation in Iran, the rain invoking custom was changed to rain prayers in which Muslims were praying and fasting for acceptance of their invoke for rain. In ancient Iran, the rain invoking custom had a long history and a praying field was in each city for rain praying.

The rain angel in the water pouring custom is changed to a Sayyid woman after the introduction of Islam to some villages of Iran. However, this custom in more developed cities of Iran is changed to a Sayyid man, who prays for the rain. Moreover, in some parts of Iran the manikin or cooking the Balghour soup have been substituted by charity gatherings of people and cooking foods for inhabitants in a mosque [1].

\section{Conclusion}

In Iran, many parts are subjected to drought and have irregular rain periods. In the past, this irregularity caused many droughts and then heavy floods in rainy 

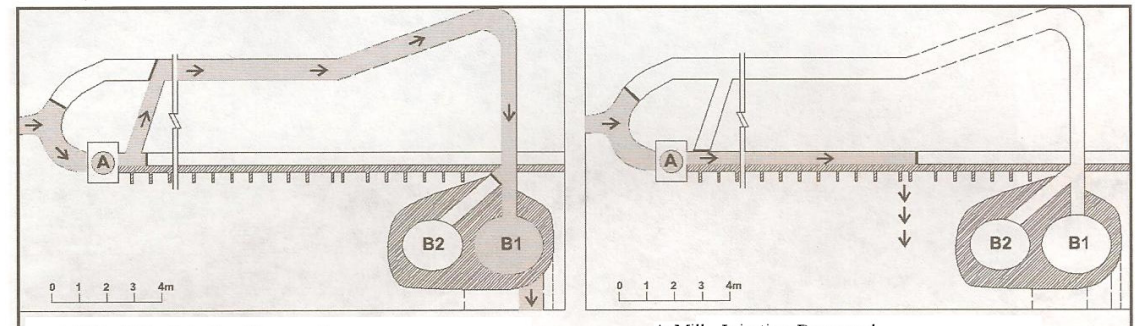

A \& B1: Mill Irrigation: Downward

A: Mill Inigation: Downward

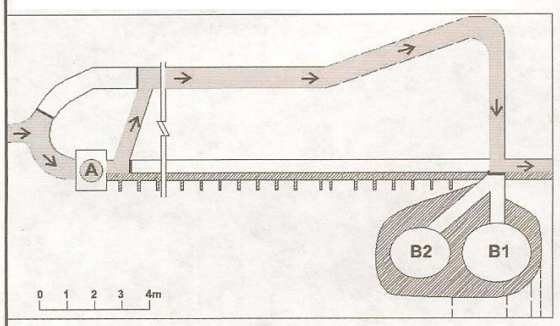

A: Mill Irrigation: Upward

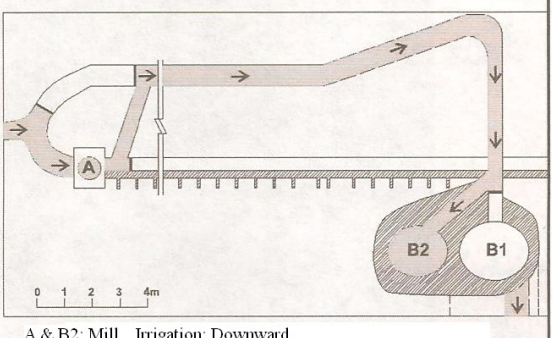

A \& B2: Mill Irrigation: Downward
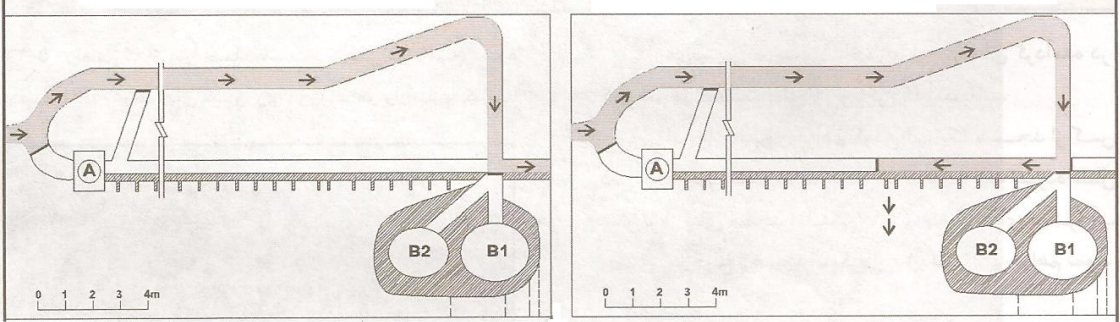

Irrigation: Upward

Inigation: Downward

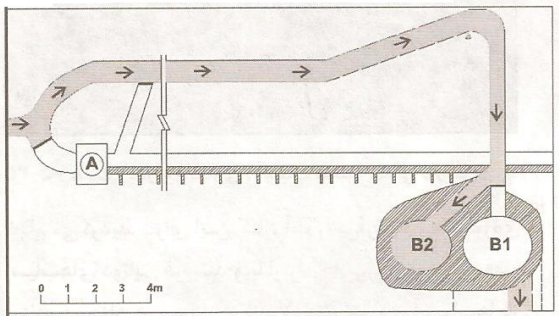

B2: Mill Irrigation: Upward

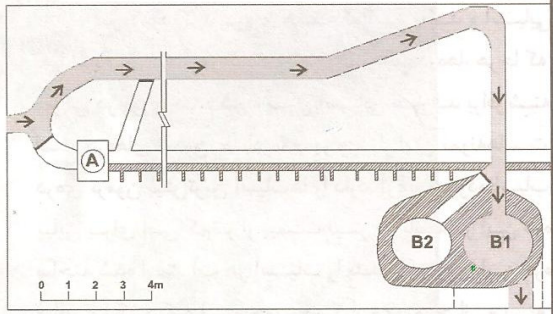

B1 : Mill Irrigation: Downward

Figure 13: Several operating conditions of the Masjed Sangi Mill and irrigation. 


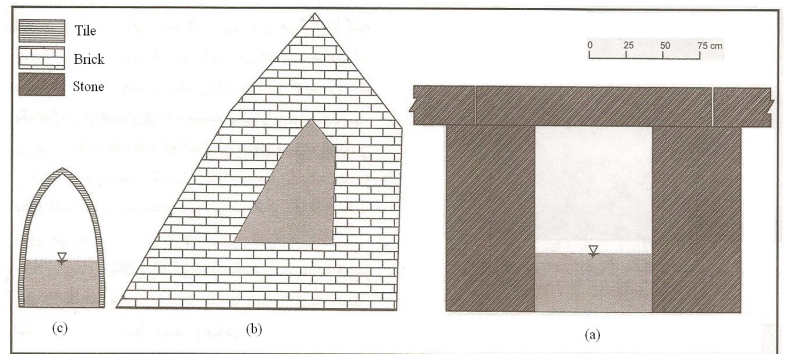

Figure 14: Different porch canals of ancient dynasties: (a) Achaemenid; (b) Zand; (c) Safavi.

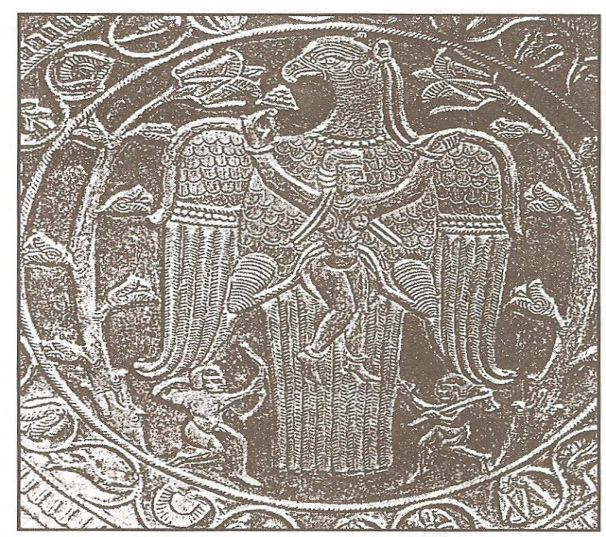

Figure 15: The Anahita goddess, Sasanian dynasty.

periods. Hence, finding a resolution for these problems by Iranians was inevitable. Iranians always solve natural disasters and also profit from them; store water in ground and underground, transfer water to different parts, applying several irrigation methods and grow plants which are endurable with special climates.

In ancient Iran, people always used applied engineering methods and best natural and manmade stuff for implementation of weirs, cisterns, mills and other water structures. Therefore, Iranians could establish powerful and vast emperors like Achaemenian and Sasanian dynasties, in this drought land. These emperors established as a result of providing infrastructures and laws for applying them. Moreover, water in Iran has had a holy and worthy value from past to now and many customs existence in Iran's culture prove this claim.

\section{References}

[1] Khalatbary, M. (2008). Water, its customs and beliefs in the national culture. Soroush Publication, Tehran. 
86 Sustainable Irrigation Management, Technologies and Policies III

[2] Safinejad, J. (1997). Water and irrigation history in Iran. In proceeding of Iran's water and irrigation conference, The irrigation and drainage committee, Shiraz.

[3] Oyoun Al-Akhbar. (1948). Water and irrigation technology in ancient Iran. Cairo, Vol. 1, 44.

[4] Javaheri, P., Javaheri, M. (2006). Water crisis in the Persian Gulf. The regional water company of Fars, Boushehr and Kohkiloye\& Boyer Ahmad. 